\title{
A utilização da análise ergonômica do trabalho como ferramenta do terapeuta ocupacional no estudo da atividade de trabalho de cabeleireiros ${ }^{1}$
}

\author{
Letícia Figueiredo da Rochaa ${ }^{\mathrm{a}}$, Angela Paula Simonelli ${ }^{\mathrm{b}, \mathrm{c}}$
}

aAcadêmica de Terapia Ocupacional, Departamento de Terapia Ocupacional, Universidade Federal do Paraná - UFPR, Curitiba, PR, Brasil

${ }^{\text {b}}$ Doutora em Engenharia de Produção, Universidade Federal de São Carlos - UFSCar, São Carlos, SP, Brasil 'Professora Adjunta, Curso de Terapia Ocupacional, Universidade Federal do Paraná - UFPR, Curitiba, PR, Brasil

\begin{abstract}
Resumo: Este artigo apresenta os resultados de uma pesquisa que objetivou analisar a atividade de trabalho de cabeleireiros, bem como demonstrar a utilidade do método da Análise Ergonômica do Trabalho (AET) como base metodológica para o terapeuta ocupacional atuar em situações de trabalho, a fim de diagnosticar os riscos ergonômicos da situação estudada e desenvolver um caderno de encargos com recomendações de melhoria. O estudo foi realizado em um salão de beleza localizado em Curitiba, PR, no período de março a outubro de 2010. A categoria profissional estudada foi "cabeleireiro" e a atividade de trabalho analisada foi "escova". Observou-se que o trabalho é realizado através da adoção de posturas inadequadas, movimentos repetitivos adicionando-se a ausência de pausas para a recuperação das estruturas musculotendíneas e/ou osteomusculares. Evidenciou-se a necessidade de intervir no ambiente de trabalho, focando-se na sua organização e pôde-se concluir que desvios observados nas atividades de trabalho desenvolvidas nesse setor de serviços refletem-se em consequências para a saúde e bem-estar dos trabalhadores.
\end{abstract}

Palavras-chave: Doenças Osteomusculares Relacionadas ao Trabalho (DORT), Ergonomia, Terapia Ocupacional.

\section{The use of ergonomic job analysis as a tool for the occupational therapist in the study of the labor activity of hairdressers}

\begin{abstract}
This article presents the results of a research that aimed to analyze the labor activity of hairdressers, as well as to demonstrate the usefulness of Ergonomic Job Analysis (EJA) work-study method as a methodological basis for the occupational therapist to act in different job situations. Through this method, the therapist is able to diagnose the ergonomic risks of the situation studied and develop a booklet of duties with improvement recommendations. The research was carried out in a hair salon located in the municipality of Curitiba, State of Parana, from March to October 2010. 'Hairdressing' was the occupational category chosen and 'hair straightening' was the work activity analyzed. It was possible to observe that the activity is performed with the adoption of inadequate posture, repetitive movements, and lack of pauses to allow the recovery of the musculotendinous and/or osteomuscular structures. The need to intervene in this working environment is noticeable, focusing on its organization. In conclusion, the disorders observed in the work activities developed in the Third Services reflect in consequences to the health and welfare of workers.
\end{abstract}

Keywords: Work-related Musculoskeletal Disorders (WMSDs), Ergonomics, Occupational Therapy. 


\section{Introdução}

O trabalho é uma atividade realizada pelo homem e reconhecida por outros como útil e, por isso, remunerada (WATANABE; NICOLAU, 2001). Tal atividade representa um aspecto imprescindível na qualidade de vida do homem, uma vez que, como todo organismo vivo, ele é submetido a um sistema de constantes transformaçóes durante sua vida; as condiçôes de trabalho de uma jornada diária cumprida durante toda a vida interferem intensamente sobre a qualidade das transformaçóes ocorridas no organismo do trabalhador (MUSSI, 2005).

Dessa forma, o trabalho pode proporcionar prazer ou sofrimento, ser estimulante e gratificante, ou maléfico à saúde física e mental do trabalhador, dependendo da situação em que o trabalho ocorre (MUSSI, 2005).

Positivamente, o trabalho pode proporcionar as mais diversas formas de realização, liberdade de criação e satisfação (MUSSI, 2005). Entretanto, negativamente, as condiçóes de trabalho podem ocasionar sequelas de curto a longo prazo, como lesóes de funções perceptivas, motoras e osteoarticulares, mentais, da personalidade e da vida extraprofissional (MUSSI, 2005).

No entanto, o mundo do trabalho vem se modificando, dentre outras razóes, devido à globalização, a redefinição do trabalho e os novos conceitos das relaçóes entre o capital e a desenvolvimento produtivo (LANCMAN, 2004).

Essas modificaçôes fazem com que surjam novas organizaçóes do trabalho (LANCMAN, 2004), o que gera um grande impacto no que diz respeito às relações entre trabalho e emprego, refletindo nas mais variadas formas de inserção no trabalho, sendo estas mais frequentes por meio da terceirização e do trabalho autônomo, refletindo em índices de desemprego, subemprego e trabalho informal cada vez maiores (LANCMAN; GHIRARDI, 2002).

Essa realidade faz com que haja uma grande mobilidade no mercado e facilita relações precárias, as quais refletem, também, nas condições de trabalho e saúde dos trabalhadores, trazendo como consequências a eles as características de cunho negativo do trabalho e tornando as características positivas cada vez mais enfraquecidas nesse processo. Os trabalhadores, por medo do desemprego, submetem-se à precarização das condiçôes de trabalho e à flexibilidade de direitos trabalhistas, acreditando que antes ter um emprego com péssimas condições a não ter emprego algum (LANCMAN; GHIRARDI, 2002).
Nessa perspectiva, este estudo, caracterizado como um subprojeto da pesquisa Interface Saúde e Trabalho - qualidade de vida nos trabalhadores de uma rede de saláo de beleza, desenvolvida pelo Departamento de Terapia Ocupacional da Universidade Federal do Paraná, ocupou-se de estudar como o trabalho pode deixar de ser prazeroso e benéfico, tornando-se adoecedor em decorrência das condições nas quais é realizado, analisando-as a fim de apontá-las e propor recomendações de melhoria.

O estudo justifica-se devido ao fato de que uma das atividades menos estudadas no âmbito da saúde do trabalhador no Brasil é a atividade de trabalho dos profissionais de estabelecimentos de beleza (MUSSI, 2005).

A atividade desses profissionais necessita de uma atenção maior do que a que vem sendo dada, visto que o crescente interesse em buscar a estética e o bem-estar e, consequentemente, o aumento da vaidade humana, refletiram em ampliação de pesquisas e avanços na área cosmetológica, gerando maior diversidade de produtos químicos, equipamentos e instrumentos de trabalho, os quais estão presentes na rotina dos salóes de beleza. Todo esse processo e essa realidade náo apenas alteraram o perfil das atividades realizadas nesses locais de trabalho, como também mudaram o perfil dos profissionais e de sua clientela (MUSSI, 2005).

Nessa perspectiva, é observado o crescimento dos serviços ofertados nesses estabelecimentos, gerando, entre eles, uma grande competição, a qual é vencida pelo somatório de diversos fatores: qualidade, rapidez, confiabilidade, flexibilidade na produção, além dos custos na produção dos serviços ali oferecidos (MUSSI, 2005).

A terapia ocupacional e a ergonomia possuem corpos teórico e prático próprios e em formação. O profissional de ergonomia procura um corpo de conhecimentos para subsidiar sua atuação, bem como o terapeuta ocupacional. A ergonomia proveniente da corrente francofônica ocupa-se da análise e compreensão do trabalhador em situaçáo real de trabalho, privilegiando a análise da atividade de trabalho em situação real, considerando os mais diversos fatores relacionados à organizaçáo do trabalho, condiçôes do ambiente, carga física e mental, entre tantos outros. Evidencia-se, dessa forma, devido à existência de diversas variáveis inseridas ao contexto do trabalho, que cada aspecto é estudado em sua singularidade própria, o que, da mesma forma, ocorre na terapia ocupacional, pois cada trabalhador, paciente ou empresa é um caso singular. 
[...] AET é um método de estudo do trabalho e a Ergonomia é uma disciplina que estuda o trabalho. Enquanto disciplina, a Ergonomia pode usar vários métodos, inclusive a AET. Enquanto método, a AET pode ser utilizada por diferentes disciplinas, inclusive a Terapia Ocupacional. (WATANABE; GONÇALVES, 2004, p. 65).

Segundo Lancman (2004), existem muitas pesquisas e intervençôes em Terapia Ocupacional que visam aprimorar a produção, as condiçốes e a organização de trabalho, porém escassas são as pesquisas e intervençôes que exploram o conteúdo do trabalho, as relaçóes particulares do trabalhador com sua atividade, consternação e desgaste advindos do trabalho e seus efeitos sobre a saúde daqueles que trabalham.

\section{Objetivo}

O objetivo deste trabalho é apresentar os resultados de uma pesquisa que objetivou analisar a atividade de trabalho de cabeleireiros, bem como, demonstrar a utilidade do método da Análise Ergonômica do Trabalho (AET) como base metodológica para o Terapeuta Ocupacional atuar em situaçóes de trabalho, a fim de, diagnosticar os riscos ergonômicos da situaçáo estudada e desenvolver um caderno de encargos com recomendaçôes de melhoria.

\section{Metodologia}

Neste estudo foram utilizadas as pesquisas exploratória para o levantamento do problema e qualitativa para a abordagem central do problema.

A pesquisa exploratória visa proporcionar maior familiaridade com o problema a fim de torná-lo explícito ou construir hipóteses. Envolve levantamento bibliográfico, entrevistas e análise de exemplos que estimulem a compreensão, assumindo, em geral, as formas de pesquisas bibliográficas e estudos de caso. Já a pesquisa qualitativa considera que há uma relação dinâmica entre o mundo real e o sujeito que não pode ser traduzida em números. Não requer o uso de métodos e técnicas estatísticas, sendo o ambiente a fonte direta para coleta de dados e o pesquisador o instrumento-chave (SILVA; MENEZES, 2001).

\section{Método}

A Análise Ergonômica do Trabalho (AET) é caracterizada como um método que decompóe e compóe o trabalho continuadamente, a fim de compreendê-lo e transformá-lo. Nesse processo não é seguida uma linearidade de etapas, já que a riqueza de sua utilização está nas idas e vindas de seu processo, as quais possibilitam uma análise crítica e total dos fatores relacionados ao trabalho (GUÉRIN et al., 2001).

Este método de análise tem como objetivo descrever a atividade de trabalho segundo a visão crítica daquele que o executa, ressaltando os princípios da análise na situação real e diferenciando o trabalho real do prescrito. Sua eficácia está pautada na transformaçáo do trabalho a partir de uma demanda real, procurando torná-lo uma atividade que além de ter um produto de cunho econômico tanto para o trabalhador quanto para a empresa, produza também desenvolvimento pessoal e profissional, além de promoção de saúde dos trabalhadores (GUÉRIN et al., 2001).

Para isso, é necessário correlacionar os mais variados fatores constituintes do trabalho que possam interferir na saúde dos trabalhadores. São de fundamental importância a compreensão da atividade do trabalho e o envolvimento dos diversos atores sociais deste processo de trabalho. Como objetivo final, a AET propóe medidas para realizar melhorias quanto aos modos de organização e execução do trabalho, a fim de torná-lo saudável aos trabalhadores e produtivo à empresa (GUÉRIN et al., 2001).

O método prevê a realização de uma análise da demanda, análise da tarefa, análise da atividade e recomendaçóes ergonômicas a fim de propor melhorias às demandas identificadas.

A análise da demanda consiste na contextualização do projeto frente à realidade da demandante, a análise da tarefa, no estabelecimento do conjunto de condicionantes que atuam sobre as situaçôes de trabalho e de uso na unidade produtiva em estudo e a análise da atividade, no estabelecimento dos aspectos determinantes das situaçóes de trabalho em uso (GUÉRIN et al., 2001).

O diagnóstico representa a recomposição das análises parciais realizadas. Os dados levantados nas análises anteriores servirão nesta fase como argumentos a serem confrontados e integrados numa síntese que reflita os aspectos determinantes da situação de trabalho (GUÉRIN et al., 2001).

O processo de análise produz um aprofundamento crescente sobre o objeto em estudo e visa o estabelecimento de um diagnóstico operante sobre a situação. $\mathrm{O}$ termo operante designa necessidade de que o processo de análise aponte para ações efetivas sobre as situaçóes, voltadas para a superação das condições iniciais encontradas e a consolidação 
de mudanças positivas nos indicadores de saúde e produtividade (GUÉRIN et al., 2001).

A etapa de síntese da análise ergonômica do trabalho inicia-se com o diagnóstico da situaçáo de trabalho que fundamentará o caderno de encargos de recomendaçôes ergonômicas (GUÉRIN et al., 2001).

As soluçôes apontadas no diagnóstico deverão ser validadas com os trabalhadores e chefias. A aprovação de uma solução deve obedecer dois critérios: deve ser adequada à atividade, sob o ponto de vista dos trabalhadores e dos gestores envolvidos, e seguir critérios ergonômicos (GUÉRIN et al., 2001).

\section{Procedimentos}

Primeiramente foi realizada revisão bibliográfica dos temas pertinentes a esta pesquisa, desenvolvida no período de março a outubro de 2010 em uma das unidades de uma rede de salóes de beleza estabelecida no município de Curitiba, PR.

Conforme prevê o método utilizado, realizou-se a análise da demanda, a análise da tarefa, a análise da atividade e recomendaçóes de cunho ergonômico para se propor melhorias às demandas identificadas. Os procedimentos da AET realizada neste estudo foram divididos em dois quadros para melhor compreensão das etapas realizadas. O Quadro 1 refere-se às fases da análise da demanda e análise da tarefa; o Quadro 2 refere-se às fases de análise da atividade, diagnóstico e recomendaçóes ergonômicas.

Os procedimentos elencados no Quadro 1 referiram-se primordialmente a uma análise documental, a qual se iniciou com a verificaçáo das açóes ergonômicas já realizadas na Rede de Salóes Marly.

Quadro 1. Análise da demanda e análise da tarefa.

\begin{tabular}{|c|c|c|}
\hline Atividades & Métodos e técnicas & Resultados esperados \\
\hline $\begin{array}{c}\text { Levantamento das ações } \\
\text { ergonômicas já realizadas na Rede } \\
\text { de Salões Marly. }\end{array}$ & $\begin{array}{c}\text { Coleta de documentos e registro de } \\
\text { experiência }\end{array}$ & Bloco de informações \\
\hline $\begin{array}{l}\text { Análise de dados de absenteísmo, } \\
\text { reabilitação e queixas }\end{array}$ & $\begin{array}{l}\text { Levantamento de dados de afastamento } \\
\text { e absenteísmo por razões médicas. } \\
\text { Levantamento de dados primários em } \\
\text { prontuários médicos e classificação } \\
\text { segundo CID } 10 .\end{array}$ & $\begin{array}{l}\text { - Dados etários e de gênero; } \\
\text { - Setores de ocorrência; } \\
\text { - Severidade; } \\
\text { - Padrões das lesões; } \\
\text { - Afastamentos; } \\
\text { - Tempo médio das lesões; } \\
\text { - Incidência atual; } \\
\text { - Lesões por tipo de atividade; } \\
\text { - Ocasião da incidência; } \\
\text { - Localização inicial do sintoma; } \\
\text { - Estágios das lesões; } \\
\text { - Histórico ocupacional. }\end{array}$ \\
\hline Determinação de indicadores & $\begin{array}{l}\text { Levantamento dos dados de } \\
\text { produção, produtividade e qualidade. }\end{array}$ & \multirow{3}{*}{$\begin{array}{l}\text { - Produtos e processos; } \\
\text { - Tecnologia; } \\
\text { - Organização do trabalho; } \\
\text { - Layout; } \\
\text { - Planejamento da produção; } \\
\text { - Setores; } \\
\text { - Postos de trabalho; } \\
\text { - Métodos de trabalho; } \\
\text { - Fatores de risco. }\end{array}$} \\
\hline Levantamento do trabalho prescrito & $\begin{array}{l}\text { Investigar se existem documentos de } \\
\text { prescrição das atividades. Caso haja, } \\
\text { realização de levantamento desses } \\
\text { documentos da rede de Salões Marly. }\end{array}$ & \\
\hline Mapeamento do processo produtivo & $\begin{array}{c}\text { Elaboração de Fichas de } \\
\text { Caracterização da Tarefa. } \\
\text { Aplicação do Ergonomics } \\
\text { Workplace Analisys. }\end{array}$ & \\
\hline Definição de situações problemáticas & $\begin{array}{l}\text { Tratamento e cruzamento das } \\
\text { informações coletadas. }\end{array}$ & $\begin{array}{l}\text { - Modelo explicativo do } \\
\text { funcionamento da unidade } \\
\text { produtiva; } \\
\text { - Modelo conceitual e hipóteses } \\
\text { explicativas para a carga de } \\
\text { trabalho; } \\
\text { - Situações de referência para } \\
\text { análise da atividade. }\end{array}$ \\
\hline
\end{tabular}

Fonte: autor (2010). 
Investigaram-se, também, informaçóes quanto à produção e à produtividade e a prescrição das tarefas, ou seja, definiram-se quais tarefas são prescritas pelo empregador a cada categoria profissional.

A partir desse primeiro contato com o saláo, levantou-se que a categoria profissional que mais apresenta problemas de saúde são os "cabeleireiros", tendo prevalência de doenças osteomusculares relacionadas ao trabalho (DORT).

Nessa perspectiva, as atividades dos cabeleireiros foram definidas como demanda inicial de análise e, após entrevistas com os trabalhadores quanto às suas atividades de trabalho, a demanda foi reformulada para a análise da atividade de escova desenvolvida por eles. A reformulação se refere à consideração da percepçáo dos trabalhadores quanto à sua carga de trabalho e as influências desta em sua saúde. Dessa forma, os sujeitos dessa pesquisa foram quatro cabeleireiros ${ }^{2}$.

Definida e reformulada a demanda e após elencadas, as tarefas foram analisadas quanto aos fatores de risco de seu desempenho: ambiente físico de trabalho, atividade física geral, levantamento de cargas, posturas e movimentos, riscos de acidente, comunicação, conteúdo do trabalho, ferramentas manuais, repetitividade, restriçóes no trabalho, tomada de decisão e atenção.

As observaçôes e registros das situaçôes de trabalho referentes aos fatores de risco foram baseados no Ergonomic Workplace Analisys (EWA) - desenvolvido pelo Instituto Finlandês de Saúde Ocupacional e adaptado pela Universidade Federal de Sáo Carlos - UFSCar (FINNISH..., 2001).

O EWA é um instrumento cuja finalidade é auxiliar na análise ergonômica do posto de trabalho. É um manual em forma de roteiro que propóe a avaliação de diversas situaçóes tanto pelo aplicador quanto pelo trabalhador daquele posto. Todas as informaçóes obtidas foram, posteriormente, validadas com os quatro trabalhadores.

O EWA agrega diferentes conhecimentos em sua base teórica: fisiologia do trabalho, biomecânica ocupacional, aspectos psicológicos, higiene ocupacional e o modelo sociotécnico da organizaçáo do trabalho. Após a coleta e o tratamento das informações coletadas desenvolveu-se um modelo explicativo para o funcionamento da unidade produtiva e hipóteses explicativas para a carga de trabalho e foram definidas as situaçôes problemáticas de referência para a análise da atividade nesta pesquisa.

Desta forma, depois de realizada a análise da tarefa quanto a seus fatores de risco, iniciou-se a etapa de análise da atividade de escova realizada pelos cabeleireiros, seguindo os métodos e técnicas apresentados no Quadro 2.

Foram selecionados três tipos de escova realizados pelos cabeleireiros a serem analisados: escova em cabelo longo e ondulado, em cabelo curto e em cabelo crespo.

Tais categorias foram escolhidas, pois, segundo relatos dos cabeleireiros, os tipos de cabelo em que a escova demanda mais esforço físico para ser feita são cabelo curto e cabelo crespo e, consequentemente, esses são os que mais causam desconfortos e dores musculares e articulares nos profissionais. Escova em cabelo longo levemente ondulado representa a maior demanda da atividade realização de escova.

Uma tabela de análise foi construída para cada tipo de escova referida, com fotos de cada uma das etapas da atividade, a cada etapa demonstrada seguia-se a descrição da mesma, a análise biomecânica e cinesiológica do cabeleireiro realizando a etapa, a quantidade de ciclos realizados durante a etapa e, por fim, o tempo gasto na realização da tarefa.

Nessas três categorias, para a análise de tais atividades foram realizados registros fotográficos e em vídeo do trabalhador em situações reais de trabalho. A partir dessas imagens foram realizadas análises cinesiológicas e biomecânicas, a fim de analisar posturas, ações, gestos, comunicações, direção do olhar, movimentos, verbalizaçôes, estratégias, modos operatórios e variaçóes de modos e dos tempos operativos.

Após, foi aplicado aos quatro cabeleireiros o questionário de percepçáo desenvolvido pelo grupo de pesquisa Ergo\&Ação da UFSCar (BERNARDINO et al., 2001), a fim de se observar o tipo de desconforto por segmento corpóreo, a relação entre desconforto e tempo de serviço na função. Tal questionário é uma avaliação direcionada ao trabalhador que busca identificar como ele analisa suas condições de trabalho (segurança, conforto, carga mental, carga física), bem como a maneira pela qual essas interferem em sua saúde.

Após a coleta de dados da situação de trabalho específica - cabeleireiros realizando a atividade de escova - foi realizada novamente revisão de literatura, com o objetivo de estudar os dados epidemiológicos, fatores de risco e intervenções ergonômicas em situaçáo similares. $\mathrm{O}$ estudo das condicionantes associadas às referências encontradas na literatura geraram hipóteses para a ação, que através de grupos focais com os trabalhadores foram refinadas e validadas quanto à organização do trabalho, variabilidade no trabalho, atividades de 
Quadro 2. Análise da atividade, diagnóstico e recomendações ergonômicas.

\begin{tabular}{|c|c|c|}
\hline Atividades & Métodos e técnicas & Resultados esperados \\
\hline Observação participante & $\begin{array}{l}\text { Registros fotográficos e em vídeo } \\
\text { dos trabalhadores em situações reais. } \\
\text { Análise cinesiológica e biomecânica }\end{array}$ & $\begin{array}{l}\text { - Registro das posturas, ações, gestos, } \\
\text { comunicações, direção do olhar, } \\
\text { movimentos; } \\
\text { - Verbalizações, raciocínios, estratégias, } \\
\text { resolução de problemas, modos } \\
\text { operatórios; } \\
\text { - Variações de modos e dos tempos } \\
\text { operativos. }\end{array}$ \\
\hline $\begin{array}{c}\text { Caracterização da percepção } \\
\text { dos trabalhadores }\end{array}$ & Questionário de percepção & $\begin{array}{l}\text { - Tipo de desconforto por segmento } \\
\text { corpóreo; } \\
\text { - Relação entre desconforto e tempo de } \\
\text { serviço na função; } \\
\text { - Atividades físicas críticas; } \\
\text { - Atividades mentais críticas; } \\
\text { - Atividades disparadoras do } \\
\text { desconforto; } \\
\text { - Correlações entre atividades físicas, } \\
\text { mentais e disparadoras; } \\
\text { - Organização do trabalho; } \\
\text { - Prazer no trabalho; } \\
\text { - Sofrimento no trabalho. }\end{array}$ \\
\hline Revisão de literatura & Pesquisa bibliográfica & $\begin{array}{l}\text { - Dados epidemiológicos em situações } \\
\text { similares; } \\
\text { - Fatores de risco em situações } \\
\text { similares; } \\
\text { - Intervenções de ergonomia em } \\
\text { situações similares. } \\
\end{array}$ \\
\hline Refinamento e validação & Grupos focais com os trabalhadores & $\begin{array}{l}\text { - Organização do trabalho; } \\
\text { - Variabilidade no trabalho; } \\
\text { - Atividade de trabalho críticas; } \\
\text { - Carga de trabalho cognitiva; } \\
\text { - Carga de trabalho organizacional; } \\
\text { - Problemas e soluções. }\end{array}$ \\
\hline $\begin{array}{l}\text { Construção do diagnóstico } \\
\text { ergonômico }\end{array}$ & $\begin{array}{l}\text { Modelo integrador da atividade de } \\
\text { trabalho }\end{array}$ & $\begin{array}{l}\text { - Síntese; } \\
\text { - Determinantes; } \\
\text { - Hipóteses para a ação. }\end{array}$ \\
\hline Recomendações ergonômicas & Ergonomic Check Point & - Caderno de encargos. \\
\hline
\end{tabular}

Fonte: autor (2010).

trabalho críticas, carga de trabalho cognitiva, carga de trabalho organizacional, problemas e soluçôes.

As hipóteses são compendiadas por meio do Modelo Integrador da Atividade (GUÉRIN et al., 2001). Tal síntese guiou a aplicação do manual Ergonomic Check Point (INTERNATIONAL..., 1996). Este manual apresenta 128 interpretaçóes ergonômicas que procuram alcançar efeitos positivos sem a necessidade de grandes custos ou soluçôes muito sofisticadas. Assim, a partir da aplicação do manual citado, tornou-se possível disponibilizar recursos realistas, por meio dos cadernos de encargos e recomendaçóes ergonômicas, que possam ser aplicados de maneira flexível e contribuir para melhorar as condiçóes de trabalho e a produtividade.

\section{Resultados}

O salão conta com 273 funcionários, desses, 50 são cabeleireiros. Os cabeleireiros recebem $55 \%$ de cada atividade que realizam e os produtos e instrumentos que nelas utilizam (cremes, tinturas, escovas, secadores de cabelo etc.) são de posse e responsabilidade do profissional. Nessa lógica, a contrapartida que recebem é a flexibilidade de jornada e frequência de dias de trabalho. Entretanto, quanto menos trabalharem menor será o salário, 
o que influencia na carência/ausência de pausas durante a jornada de trabalho.

Para o levantamento dos indicadores de produção referentes à atividade analisada - escova -, quatro cabeleireiros foram abordados e, junto a eles, um quadro foi construído:

Segundo o Quadro 3, até por volta do dia 20 o movimento costuma ser maior, pois esse é o período em que a maioria dos clientes recebe o salário; no final do mês, entre os dias 21 e 30, o movimento diminui, evidenciando-se assim um movimento sazonal no salâo. Entretanto, essa lógica nem sempre se confirma, pois se ocorre algum evento, como casamentos, formaturas, mesmo nos dias situados no final do mês o movimento pode ser alterado.

Assim, chegou-se à estimativa de que por mês cada cabeleireiro realiza em média 134 escovas. Esse número é justificado pelos trabalhadores, os quais relatam que a escova não é realizada apenas de forma individual. Afirmam que a maioria dos procedimentos realizados são ou precedidos de uma escova, como a realização da escova definitiva, ou seguidos de uma escova, como um corte.

Por meio da aplicação do EWA pôde ser constatado que as situaçóes que se encontram irregulares são: espaço de trabalho, atividade física geral, posturas e movimentos, riscos de acidente, restriçôes no trabalho, repetitividade do trabalho, atenção, iluminação e ruído.

O espaço de trabalho é relativamente pequeno para o trabalhador, pois uma bancada situa-se ao lado da outra, devido ao grande número de profissionais da mesma categoria. Somado a isso, existe o fato de o cabeleireiro muitas vezes dividir seu espaço com outro profissional, principalmente a manicure, a fim de aumentar a velocidade do atendimento à cliente. Essa prática é comum neste saláo, já que a característica dele é a rapidez e a qualidade no serviço ao cliente.

Quanto à atividade física geral, essa é considerada intensa, pois dificilmente os cabeleireiros realizam pausas entre um atendimento e outro, já que é necessária rapidez na prestação do atendimento.

Com relaçáo às posturas e movimentos, de igual forma são considerados danosos à saúde dos cabeleireiros devido à inexistência de pausas durante a jornada de trabalho.

A atividade analisada demanda grande atenção do trabalhador que a executa. Com a atividade intensificada, sem períodos de descanso, o nível e capacidade de atenção do trabalhador podem ficar comprometidos.

Os cabeleireiros relataram que existem restriçóes, principalmente de cunho organizacional da tarefa - tempo para realizá-la, dependem do trabalho das auxiliares de cabeleireiro. Além disso, existem também situaçôes em que estão realizando um procedimento em um cliente e outro já está aguardando. Nesses casos, os cabeleireiros ficam com seu tempo ainda mais restrito, o que restringe a atividade de trabalho deles.

Quanto aos problemas identificados nos itens iluminação e ruído, apesar da impossibilidade de se utilizar aparelhos de mensuração desses itens neste estudo, foi observado e confirmado pelos profissionais que a iluminação era deficiente no ambiente, necessitando de uma maior luminosidade durante a realização das atividades. Relataram ainda que muitas vezes as lâmpadas queimam e demoram dias para serem trocadas.

Quanto ao nível de ruído, ele se encontra acima do que os profissionais consideram confortável e saudável para a realização de suas atividades, contribuindo para a irritabilidade dos profissionais, que relatam que mesmo depois, em casa, têm a impressão de estar ouvindo aquele barulho, até para a ocorrência de dores de cabeça, tornando baixa a qualidade de vida no trabalho.

A partir da análise da atividade escova foi possível descrever as etapas pelas quais ela é realizada (Quadro 4).

Foram selecionados três tipos de escova para a análise: escova em cabelo curto, em cabelo crespo e em cabelo longo levemente ondulado.

Por meio das análises dos dados, chegou à estimativa que a escova em cabelo curto despendeu 13 minutos; a etapa mais trabalhosa é a de número 7 , tomando cerca de 8 minutos e apresentando 17 ciclos. A escova em cabelo longo levemente ondulado

Quadro 3. Indicadores mensais de produção referentes à atividade escova.

\begin{tabular}{|c|c|c|c|c|c|c|}
\hline Dia da semana & Segunda & Terça & Quarta & Quinta & Sexta & Sábado \\
\hline Dias do mês & & & & & & $15-20$ \\
\hline Do dia 1 ao dia 20 & $5-6$ & 8 & $8-10$ & $8-10$ & $15-20$ \\
\hline
\end{tabular}

Fonte: autor (2010) 
Quadro 4. Etapas da atividade escova.

A cliente chega à cabeleireira com os cabelos lavados, levemente molhados.

\begin{tabular}{|c|l|}
\hline \multicolumn{2}{|c|}{ A cliente chega à cabeleireira com os cabelos lavados, levemente molhados. } \\
\hline Etapa & \multicolumn{1}{c|}{ Descrição } \\
\hline 1 & Desembaraçar o cabelo com a escova. \\
\hline 2 & $\begin{array}{l}\text { Secar parcialmente o cabelo, chacoalhando-o com uma das mãos e utilizando-se do secador, com a } \\
\text { outra, até o cabelo estar parcialmente seco. }\end{array}$ \\
\hline 3 & $\begin{array}{l}\text { Separar o cabelo, deixando uma mecha de cabelo na parte inferior, enrolar o restante e o prender } \\
\text { para cima, se não for muito curto. }\end{array}$ \\
\hline 4 & $\begin{array}{l}\text { Enrolar a mecha que está solta na escova em uma de suas mãos, puxando-a de forma que o cabelo } \\
\text { vá se desenrolando forçadamente da escova e, simultaneamente, passar o secador na parte que está } \\
\text { sendo solta. }\end{array}$ \\
\hline 5 & A etapa 4 é repetida na mesma mecha quantas vezes forem necessárias. \\
\hline 6 & Soltar o cabelo preso, retirar uma mecha e prender o restante da mesma forma. \\
\hline 7 & Repetir a etapa 4, 5 e 6 até todo o cabelo ser solto e escovado. \\
\hline 8 & Usar o secador e a mão para jogar todo o cabelo da cliente para trás. \\
\hline 9 & Arrumar todo o cabelo conforme o gosto da cliente. \\
\hline 10 & Mostrar, com auxílio de mais um espelho, como a escova ficou. \\
\hline
\end{tabular}

despendeu 14 minutos; a etapa mais trabalhosa, de igual forma, é a de número 7 , tomando cerca de 11 minutos e apresentando 22 ciclos. Já a escova em cabelo crespo despendeu cerca de 1 hora e 5 minutos; a etapa mais trabalhosa, assim como nas outras duas escovas, é a de número 7 , tomando 54 minutos e apresentando 23 ciclos.

Evidenciou-se que durante a realização da atividade ocorre sobrecarga postural em coluna vertebral e membros inferiores devido à permanência por períodos prolongados de tempo na postura em pé.

Os membros superiores são extremamente exigidos com relação aos movimentos repetitivos e manutençáo dos mesmos em extensão por longos períodos de tempo.

Foi evidenciada nesta análise que, durante a realização da atividade, o membro superior que segura a escova permanece na postura alternada de flexão-extensão do ombro, associada à abdução do ombro. O punho varia de flexão total a extensão total. Essa postura é associada muitas vezes ao desvio ulnar e radial, fato esse que leva à sobrecarga nessa região.

As articulaçôes metacarpofalangianas permanecem fletidas durante toda a atividade, para segurar escova e secador. A maior parte da atividade é realizada com os membros superiores em extensão, o que gera um aumento de tensão na região cervical.

De maneira geral, essa atividade gera sobrecarga postural em coluna lombar e cervical e em membros superiores, principalmente devido à manutenção dos membros superiores elevados, distantes do corpo e em posiçôes não anatômicas, como a flexão/extensão de punho, flexáo de dedos, desvio ulnar e radial e prono/supinação de punho/antebraços. Além disso, há uma sobrecarga muscular e vascular em membros inferiores devido à permanência em pé por períodos prolongados de tempo.

A partir do questionário de percepção, os cabeleireiros afirmaram que apresentam dores moderadas em ombros e coluna alta e dores fortes em coluna baixa e cotovelos e atribuem à atividade escova a maior responsabilidade pelos sintomas.

\section{Discussão}

A partir dos resultados elencados por meio da análise dos dados coletados de acordo com o procedimento explicitado e de sua articulação com a literatura específica, serão aqui apresentadas a construção do diagnóstico ergonômico e as recomendaçôes ergonômicas realizadas neste estudo. Justifica-se a estruturação do texto devido a esta etapa do método discutir os resultados coletados com a literatura acerca do tema a fim de apresentar um diagnóstico que representa a recomposição das análises parciais realizadas para a proposição de melhorias que devem estar adequadas à atividade realizada, sob o ponto de vista dos trabalhadores, dos gestores envolvidos e dos critérios ergonômicos.

\section{Construção do diagnóstico ergonômico}

Com base nas informaçôes obtidas pelo EWA, pelo questionário de percepção e dados das análises da atividade foi possível se chegar a um diagnóstico ergonômico da situação estudada. 
Com relação ao EWA, exceto os itens iluminação e ruído, os demais são influenciáveis pela maneira que a organização do trabalho é estruturada no local. Por serem autônomos e receberem pouco mais da metade de tudo que produzem, para receber um salário considerado bom os cabeleireiros devem atender o máximo de clientes possível. Eles evitam as pausas, pois nesse momento um cliente pode chegar e ser passado para outro cabeleireiro. Segundo a própria empregadora, é solicitado a eles que evitem almoçar no horário habitual, pois esse é um dos maiores picos de movimento no saláo. Segundo os cabeleireiros, nos finais de semana o movimento é ainda mais intenso e muitas vezes passam o dia sem pausa alguma, o que influencia no registro de problemas nos itens atividade física geral, posturas e movimentos, riscos de acidente, repetitividade do trabalho e atenção.

Segundo Assunção e Almeida (2003), as DORT aparecem, principalmente, quando há um desequilíbrio entre as exigências das tarefas e as margens deixadas pela organização do trabalho para o trabalhador, durante a execução de suas atividades, obrigando o trabalhador a mobilizar suas competências dentro de suas possibilidades.

O trabalhador pode conseguir regular a repetição dessa ação de exigência biomecânica por meio de quatro mecanismos: alívio do esforço, alternância de exigências, descanso entre jornadas e por meio do hormônio somatotrófico, o qual atua durante o sono sobre os tecidos lesionados ao longo do dia, removendo as células mortas e restaurando a integridade tecidual. Entretanto, dependendo do nível de exigência da atividade, a regulação não é possível de ser alcançada (SILVA, 2009).

Dessa forma, ocorrem alteraçóes musculares, tendíneas e neurológicas - fadiga muscular, ruptura de miofibrilas, processo inflamatório, aumento de potássio e de cálcio intracelular, tração muscular, compressáo contra tecidos, atrito nos tendóes e entre as estruturas vizinhas - que ocasionam diminuição de força muscular e processo de dor crônica, quadro clínico que corresponde à DORT (SILVA, 2009).

A inexistência de pausas pode ser considerada uma das principais causadoras desse quadro, pois, segundo Przysiezny (2000) e Verthein e MinayoGomez (2000), o trabalhador que, entre outros aspectos, inclui intervalos para descanso durante a jornada de trabalho apresenta maior probabilidade de desempenhar suas atividades sem prejuízo de sua saúde. $\mathrm{O}$ mesmo autor complementa que uma organização do trabalho adequada não apresenta alta incidência de patologias musculoesqueléticas.
Dessa forma, evidencia-se que apesar de a própria atividade de escova ser danosa à saúde do trabalhador, pela alta repetitividade de movimentos, posturas adotadas inadequadas, grande atividade física despendida, como pôde ser evidenciado pelas análises da atividade principalmente quando ela é realizada em cabelo crespo comprido, o fator mais agravante e primordial para a presença da alta incidência e prevalência de DORT entre os cabeleireiros do saláo estudado foi o fato de não existirem pausas.

Com relação à problemática encontrada nos itens espaço de trabalho e restriçốes no trabalho, esses também podem ser atribuídos à organização do trabalho, a qual preconiza a rapidez e qualidade no atendimento ao cliente e, dessa forma, o espaço de trabalho, que já é pequeno devido ao grande número de cabeleireiros, pode se tornar ainda mais limitado quando dividido com outros profissionais no caso de o cliente desejar ser atendido por mais de uma categoria profissional.

Esta pode ser considerada uma restrição ao trabalho do profissional, além da restrição quanto à dependência da auxiliar de cabeleireiro, a qual deve atender ao cliente antes do cabeleireiro, e a restrição quanto à realização do trabalho de maneira tranquila, já que a empregadora delibera no máximo 30 minutos para a realizaçáo de cada escova, independente do tamanho e tipo de cabelo, o que, pela análise da atividade, foi comprovado ser impossível quando o cabelo é crespo, evidenciando disparidade entre o conhecimento daquele que elabora a tarefa (empregador) e aquele que executa a atividade (cabeleireiro).

Quanto aos problemas identificados nos itens iluminação e ruído, bem como em relação ao espaço de trabalho, esses são fatores pontuais que devem ser adequados seguindo a Norma Regulamentadora n. 17 (NR 17) (BRASIL, 1999), referente aos aspectos ergonômicos.

Evidencia-se, portanto, que existe um alto risco de os cabeleireiros deste saláo desenvolverem uma DORT devido à sua atividade, comprovado pelas análises da atividade e organização de trabalho a que estão submetidos, fato evidenciado pela literatura, pela demanda trazida pela empregadora, confirmada com os trabalhadores e comprovada pelo resultado do EWA e do questionário de percepção.

\section{Recomendações ergonômicas}

Complementando as disposições encontradas na NR 17 (BRASIL, 1999) e NBR 5413 (ASSOCIAÇÃO..., 1992), a ILO (INTERNATIONAL..., 1996), por meio 
do Ergonomic Check Points, recomenda que o local de trabalho seja iluminado de maneira a que as oscilaçóes de luminosidade sejam corrigidas, proporcionando iluminação suficiente para os trabalhadores, para que eles possam desempenhar suas atividades a todo o momento de forma eficiente e confortável. Além disso, destaca-se neste documento a importância de se realizar periodicamente a limpeza de janelas e a manutenção das fontes de luz, sendo esse última uma demanda trazida pelos trabalhadores do salão de beleza.

Assim como sugerido por Mussi (2005), sugere-se a utilização de secadores de cabelo mais silenciosos, entretanto os materiais utilizados são de posse do cabeleireiro, sendo, de igual forma, de sua responsabilidade a adoçáo de um novo instrumento de trabalho. Outra recomendação também sugerida por Mussi (2005) e que seria de responsabilidade da proprietária do saláo seria a instalaçáo de material com mecanismos antirruído nas paredes, o qual absorveria o som e evitaria, assim, sua reflexão.

Como visto durante toda a pesquisa, a razão pela qual existem grande incidência e prevalência de DORT no saláo estudado é a maneira como a organizaçáo do trabalho é estruturada. Nessa vertente, o fator primordial é a forma de vínculo empregatício, o qual não fornece segurança ao trabalhador que necessita trabalhar constantemente, sem pausas, em uma jornada de trabalho grande para receber um salário considerado bom.

Assim, uma possível solução seria a contratação formal desses cabeleireiros, combinada ao sistema de comissóes. Nesse vínculo empregatício, os cabeleireiros, como qualquer trabalhador contratado formalmente, teriam deliberada a jornada de trabalho, bem como os dias de trabalho e a meta que cada trabalhador deve alcançar durante o mês. Nessa meta seria deliberado, conforme sugere a ILO (INTERNATIONAL..., 1996), o número de tarefas que cada trabalhador deve realizar por meio da combinação entre as variadas tarefas que o profissional executa, visto que algumas atividades são mais penosas que outras, como evidenciado no caso da escova.

Assim, os cabeleireiros receberiam um salário fixo e, quando excedida a meta, receberiam ainda a porcentagem estabelecida por acordo entre empregadora e empregados. É importante que a meta não seja prejudicial à saúde do profissional e que a comissão não seja tão atrativa a ponto de o trabalhador negligenciar sa própria saúde por ela.

Essa possibilidade refletiria em maior segurança para os cabeleireiros, quanto ao salário e aos direitos trabalhistas, e maior produtividade ao salão, que contaria com todos os profissionais disponíveis em tempo integral, para o atendimento de um número maior de clientes.

O tipo de vínculo de trabalho dos cabeleireiros do salấo estudado foi idealizado levando-se em conta que devido ao grande número de profissionais e à característica de o estabelecimento em estudo ser um saláo com preços acessíveis à mais variada clientela, não seria possível fornecer um salário considerado bom para os profissionais sem diminuir a quantidade ou sem elevar o preço dos serviços, medidas que iriam contra a característica do salão: rapidez no atendimento e acolhimento da demanda espontânea pela quantidade de profissionais disponíveis e acessibilidade ao serviço.

Algumas outras recomendações apontadas pela ILO (INTERNATIONAL..., 1996), por meio do Ergonomic Check Points, e aplicáveis ao caso analisado envolvem a participação dos trabalhadores nas decisóes quanto ao seu trabalho por meio de encontros periódicos entre eles e seus superiores. Nesses encontros, os trabalhadores apresentariam problemas e dificuldades que vêm encontrando na realizaçấo de suas atividades, bem como possíveis soluçôes, confrontando-se o ponto de vista dos cabeleireiros e dos superiores.

Envolver o trabalhador nas decisóes quanto a seu próprio trabalho fornece ao profissional maior autonomia, poder de controle e criatividade em sua atividade, refletindo num maior envolvimento dos trabalhadores com sua atividade.

Evidencia-se que, em geral, os desvios observados na produção, em uma empresa, ou no setor de serviços, refletem-se em consequências para a saúde e bem-estar dos trabalhadores, correlacionando-se tal fato ao desconhecimento das atividades de trabalho ali desenvolvidas e dos próprios limites desses trabalhadores. Essa situação decorre de se considerar que os trabalhadores têm uma capacidade de adaptação infinita, como se funcionassem constantemente, sem consequências para a saúde e vida social (GUÉRIN et al., 2001).

\section{Considerações finais}

A literatura pesquisada apontou que o trabalho apresenta aspectos positivos para aquele que o executa; entretanto, por meio da realização deste estudo foi possível observar na prática outra evidência apontada pela literatura: o trabalho pode deixar de ser prazeroso e positivo, tornando-se penoso, adoecedor quando realizado em condições inadequadas.

Foi demonstrado através das análises dos dados coletados e dos relatos dos trabalhadores participantes da pesquisa que quando o trabalho é realizado adotando-se posturas inadequadas, com movimentos 
repetitivos e carência/ausência de pausas para a recuperação das estruturas musculotendíneas e/ou osteomusculares, a incidência e prevalência de DORT entre esses trabalhadores é elevada, fato previamente pontuado na literatura e também considerado norteador da pesquisa, ou seja, a demanda para a realização deste estudo, apresentada pelo empregador.

Verificou-se, por meio deste estudo, que as características da atividade que os cabeleireiros desenvolvem neste salão contribuem para o desenvolvimento de doenças osteomusculares.

Dessa forma, é vital agir sobre as condiçôes de trabalho para a prevenção adequada dos efeitos negativos delas sobre o corpo do trabalhador, pois a partir do início da sua vida laboral inicia-se o processo que determinará o seu estado de saúde futuramente, bem como sua perspectiva de vida.

Pôde-se evidenciar a importância da AET no processo de análise da atividade de trabalho do cabeleireiro, pois esta se mostrou complementar à análise da atividade que compete ao terapeuta ocupacional, através de sua formaçáo acadêmica, realizar. Em sua atuação, o terapeuta ocupacional possui uma visão holística da situação em que deve intervir, o que se complementou com a AET, que tem como objetivo partir de uma visão macro da empresa e intervir nas microssituaçóes a fim de alcançar uma melhoria do todo.

Nessa perspectiva, a AET caracteriza-se como um método que leva em consideração os diferentes pontos de vista sobre o processo de trabalho (empregados e empregadores) a fim de confrontá-los, procurando soluçôes eficazes para as demandas encontradas. Nesse processo, o terapeuta ocupacional, utilizando-se da AET, é capaz de intervir de modo eficaz e favorável para os trabalhadores e para os empregadores.

\section{Referências}

ASSOCIAÇÃO BRASILEIRA DE NORMAS TÉCNICAS - ABNT. NBR 5413 (1992): Iluminancia de Interiores. Rio de Janeiro: ABNT, 1992. Disponível em: <http://www.labcon.ufsc.br/anexos/13.pdf>. Acesso em: 24 out. 2010.

ASSUNÇÃO, A. A.; ALMEIDA, I. M. Doenças osteomusculares relacionadas com o trabalho: Membros superiores e pescoço. In: MENDES, R. Patologia do trabalho. 2. ed. São Paulo: Atheneu, 2003. p. 1501-1539.

BERNARDINO, M. T. S. M. et al. Questionário de Percepşão. São Carlos: UFSCar, 2001. Disponível em: <www.simucad. dep.ufscar.br>. Acesso em: 05 maio 2010.

BRASIL. Ministério do Trabalho e Emprego. Norma Regulamentadora no 17 Ergonomia. In: BRASIL. Ministério do Trabalho e Emprego. Normas Regulamentadoras. Brasília: MTE, 1999. Disponível em: <http://www.mte.gov.br/legislacao/normas_ regulamentadoras/nr_17.pdf>. Acesso em: 08 jun. 2010.
FINNISH INSTITUTE OF OCCUPATIONAL HEALTH. Análise Ergonômica do Posto de Trabalho. Tradução de João Alberto Camarotto. São Carlos: UFSCar/DEP, 2001. Título original: Ergonomic Workplace Analisys (EWA). Disponível em: <http://www.simucad. dep.ufscar.br/110345_Ergonomia_graduacao_1_2008/ ewa.pdf >. Acesso em: 05 maio 2010.

GUÉRIN, F. et al. Compreender o trabalho para transformá-lo: a prática da ergonomia. 2. ed. Sáo Paulo: Edgard Blücher LTDA, 2001.

INTERNATIONAL LABOR OFFICE - ILO. Ergonomic Check Points: pratical and easy-to-implement solutions for improving safety, health and working condutions. Geneve: ILO, 1996.

LANCMAN, S. Construção de Novas Teorias e Práticas em Terapia Ocupacional, Saúde e Trabalho. In: LANCMAN, S. Saúde, trabalho e terapia ocupacional. São Paulo: Roca, 2004. p. 71-83.

LANCMAN, S.; GHIRARDI, M. I. G. Pensando em Novas Práticas em Terapia Ocupacional, Saúde e Trabalho. Revista de Terapia Ocupacional da Universidade de São Paulo, São Paulo, v. 13, n. 2, p. 44-50, 2002.

MUSSI, G. Prevalência de Distúrbio Osteomuscular Relacionados ao Trabalho (LER/DORT) em profissionais Cabeleireiras de Institutos de Beleza de dois distritos da cidade de São Paulo. 2005. 156 f. Tese (Doutorado em Saúde Coletiva)-Universidade de São Paulo, São Paulo, 2005.

PRZYSIEZNY, W. L. Distúrbios Osteomusculares Relacionados ao Trabalho: um enfoque ergonômico. Ensaios de Ergonomia, Florianópolis, jun. 2000. Disponível em: $<$ http://www.eps.ufsc.br/ergon/revista/artigos/disturbios. PDF>. Acesso em: 08 jun. 2010.

SILVA, E. L.; MENEZES, E. M. Metodologia da pesquisa e elaboração da dissertação. 3. ed. rev. atual. Florianópolis: Laboratório de Ensino a Distância da UFSC, 2001. Disponível em: <http://projetos.inf.ufsc.br/arquivos/ Metodologia\%20da\%20Pesquisa\%203a\%20edicao.pdf $>$. Acesso em: 06 jul. 2010.

SILVA, V. M. C. LER/DORT. Juiz de Fora: Centro de Estudos, Departamento de Saúde do Trabalhador - DSAT, 2009. Disponível em: <http://webcache.googleusercontent.com/ search?q=cache:ZpdFEQ3ha3gJ:www.cmrbjf.com.br/ler. ppt+doen\%C3\%A7a+osteomuscular+relacionada+ao+tra balho+mecanismo\&cd $=8 \& \mathrm{hl}=\mathrm{pt}-\mathrm{BR} \& \mathrm{ct}=\mathrm{clnk} \& \mathrm{gl}=\mathrm{br}>$. Acessado em: 06 jul. 2010.

VERTHEIN, M. A. R.; MINAYO-GOMEZ, C. A construção do "sujeito-doente" em LER. História, Ciências, Saúde-Manguinhos, Rio de Janeiro, v. 7, n. 2, p. 329-347, out., 2000. http://dx.doi.org/10.1590/ S0104-59702000000300005

WATANABE, M.; GONÇALVES, R. M. A. Relaçôes conceituais entre terapia ocupacional e ergonomia. In: LANCMAN, S. Saude, trabalho e terapia ocupacional. São Paulo: Roca, 2004. p. 19-70.

WATANABE, M.; NICOLAU, S. M. A terapia ocupacional na interface da saúde do trabalhador. In: DE CARLO, M. M. R. P.; BARTALOTTI, C. C. C. Terapia Ocupacional no Brasil: fundamentos e perspectivas. São Paulo: Plexus, 2001. p. 155-171. 


\section{Contribuição dos Autores}

Letícia Figueiredo da Rocha: desenvolveu a pesquisa e redigiu o manuscrito. Angela Paula Simonelli: orientou o desenvolvimento da pesquisa, do manuscrito e revisou o manuscrito.

\section{Notas}

${ }^{1}$ Este estudo, trabalho de conclusão de curso, caracterizou-se como parte integrante do projeto de pesquisa Interface Saúde e Trabalho - qualidade de vida nos trabalhadores de uma rede de saláo de beleza apresentado e aprovado pelo Conselho de Educação e Pesquisa (CEP) do Setor de Ciências da Saúde da Universidade Federal do Paraná, realizado nas unidades de uma rede de salóes de beleza no período de março a outubro de 2010.

${ }^{2}$ Vale ressaltar que nesse método o número de sujeitos não interfere nos resultados, visto que se busca analisar o trabalho e não o sujeito. 